\title{
Characteristic and Efficiency Analysis of Storage-type Solar PV/Thermal Hybrid System
}

\author{
Feng-Chin Tsai ${ }^{1, *}$, Xin-Zhi Huang ${ }^{2}$ \\ ${ }^{1}$ Department of Mechanical Engineering, Tungnan University, Taiwan \\ ${ }^{2}$ Institute of Mechanical Engineering, Tungnan University, Taiwan
}

Copyright $(2016$ by authors, all rights reserved. Authors agree that this article remains permanently open access under the terms of the Creative Commons Attribution License 4.0 International License

\begin{abstract}
Storage-type solar PV/thermal hybrid system added a water tank below the PV panel directly is to cool the surface of PV chip and reuse the waste heat. Solar test equipment was set up to adjust irradiation amount of halogen lamp to light on solar PV board and measure the I-V curves of the PV panel simultaneously. Surface temperature of PV panel and water temperature of water tank are measured respectively by infrared thermal imager and thermocouples. By altering the irradiation of $600 \sim 900 \mathrm{~W} / \mathrm{m}^{2}$ at a $30^{\circ}$ inclination angle of PV panel, the experience data of storage-type solar PV/thermal hybrid system can be got, total efficiency transformed by photovoltaic efficiency and hot water efficiency of $\mathrm{PV} /$ thermal hybrid system can be analyzed. The results show that total efficiency of storage-type solar PV/thermal hybrid system is more excellent as compared to the pure photovoltaic efficiency. The hot water efficiency of $\mathrm{PV} /$ thermal hybrid system from recycling waste heat gets $38 \sim 40 \%$. If the electric/heat energy conversion efficiency is about 0.38 , total efficiency transformed obtains more efficiency about $14 \sim 15 \%$ from the recycling the waste heat. The total efficiency of storage-type solar PV/thermal hybrid system is almost 4 times than photovoltaic efficiency in experimental surrounding.
\end{abstract}

Keywords PV/thermal, Storage-type, Total Efficiency

\section{Introduction}

Solar PV panel has been considered as the best renewable among the developable energy. The related technological application matures gradually. When solar PV panel is shined, the surface temperature of solar PV panel is increased. With the impact of heat, PV efficiency drops and lifetime cuts down also. Solenki et al. [1 2] set up a V-trough PV module to let the reflected lights fall on the PV panel inside the V-trough PV module to get its efficiency. The efficiency of $10.57 \%$ in normal solar PV panel can be measured at the sunlight amount of $750 \mathrm{~W} / \mathrm{m}^{2}$, while the efficiency of $17.1 \%$ in V-trough PV module can be presented. Akbarzadeh and Wadowski [3] set up a cooling PV chip system, which focused sunlight with its reflector and cool down the surface temperature of the chip with cooling fins and heat pipes in the back of the PV chip. The surface temperature of the chip decreased $20^{\circ} \mathrm{C}$, and the output power increased $10 \mathrm{~W}$.

Many scholars referred to the research that solar PV panel can be cooled down with water to improve its efficiency [4 6]. Krauter [7] set a water tank above PV panel with multiple water pipes releasing water through the upper surface of the panel to cool it down. The surface temperature of the panel decreased obviously.

Combining solar PV panel with solar heat collector is another concept to improve the overall efficiency [8 10]. Hollick [8] laid solar PV panels above a wave board painted with dark-color that could easily to absorb irradiation wavelength. This is the combination of solar photoelectric conversion by PV panel and solar hot water by heat conversion, what we called PV/thermal (or PV/T) system.

Tonui and Tripanagnostopoulos [9] made use of air to cool PV panel and indirectly transferred heat to liquid, constructing a PV/thermal solar energy collector. Kumar and Tiwari [10] set a solar PV panel beside the stored solar water heating tank to form a PV/thermal system-and improved the overall efficiency to more than $52 \%$.

This research is to recycle the waste heat from solar PV panel during the photoelectric conversion process. Normal solar hot water absorbs irradiation energy with heat collector, and converses solar energy to heat the water in the sink.

A storage-type solar PV/thermal hybrid system added directly a storage tank below the PV panel directly to cool the surface of PV panel. Solar PV test equipment has constructed to adjust the irradiation amount of halogen light. When the light irradiate on the solar PV panel, voltage and current of PV panel can be measured with I-V curve measurer and drawn an I-V curve to analyze the efficiencies. This experiment was carried out with different irradiation of $600 \sim 900 \mathrm{~W} / \mathrm{m}^{2}$ and 30 oinclination angel of $\mathrm{PV} /$ thermal 
system to obtain the total efficiency and the surface temperature of the solar PV panel. During the photoelectric conversion process of solar PV panel, the waste heat on the surface will affect conversion efficiency. Total efficiency of a storage-type solar PV/thermal hybrid system combining photovoltaic efficiency of PV panel and hot water efficiency of solar hot water system can be obtained.

\section{Methods}

Voltage and electric current of PV chip is always tested when absorbing different irradiation to form a I-V curve and get the efficiency. As shown in figure 1, the numbers of voltage and electric current were measured at different loads to form the I-V curve. There are five important parameters in the I-V curve. $I_{s c}$ and $V_{o c}$ are the short-circuit current and open-circuit voltage. The point $P_{\max }$ shows the maximum power at the I-V curve, and $I_{\max }$ and $V_{\max }$ are defined as the electric current and voltage at the $P_{\max }$ position.

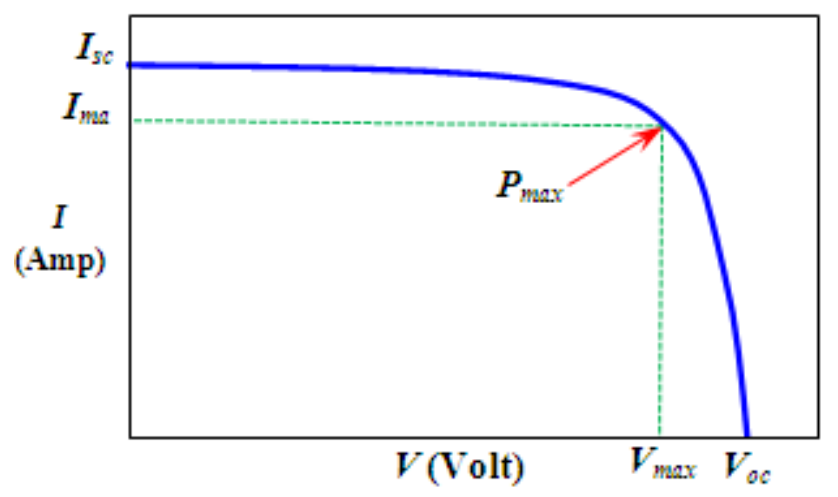

Figure 1. The characteristic curve of solar PV chip

Figure 2 shows the correlation chart between I-V curves with different irradiation amount. I-V curve promotes with increases of irradiation. The short-circuit current $I_{s c}$ and open-circuit voltage $V_{o c}$ are also increase with increases of irradiation. Figure 3 shows the correlation chart between I-V curves and surface temperature at the same irradiation. I-V curve reduces with the increases of surface temperature at the same sunlight amount. Then, conversion efficiency of PV panel reduces also with the increases of surface temperature. It reveals that the efficiency of PV chip is affected obviously by the surface temperature of solar PV.

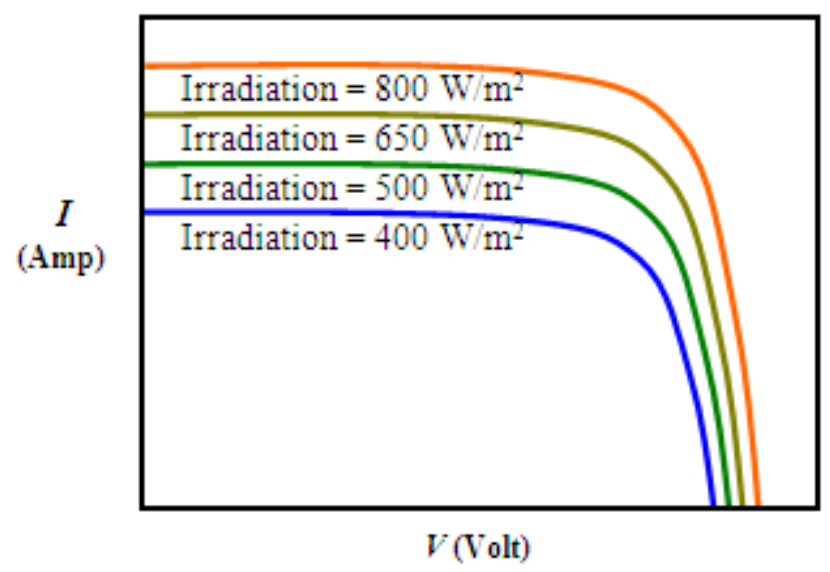

Figure 2. The correlation chart between $I-V$ curves with different irradiation

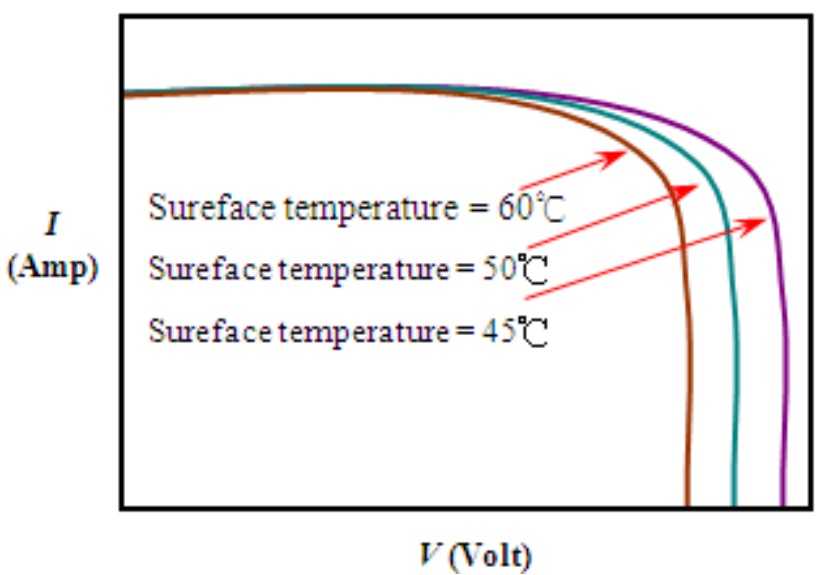

Figure 3. The correlation chart between I-V curves and surface temperature at the same irradiation

The surface heat generated at the irradiating solar PV panel can be cooled; the waste heat can be used to become hot water. It forms the structures of PV/thermal hybrid system. This hybrid system not only can cool the surface of the solar PV panel, but can recycle the waste heat without pump pressurization. The solar energy can be applied effectively.

The experimental data of PV/thermal hybrid system at different irradiation can be measured, including I-V curve, surface temperature distribution of PV panel, and water temperature inside the water tank below the PV panel. Photovoltaic efficiency and hot water efficiency can be calculated by the efficiency equations. Then, the best design parameters to promote the total efficiency of the PV/thermal hybrid system can be got from our experiments. 
Several efficiencies in this research can be defined and calculated as follows. Photovoltaic efficiency of the PV panel, $\eta_{e}$, can be defined as:

$$
\eta_{e}=\frac{P_{\max }}{I(t) \cdot A_{c}} \cdot 100 \%
$$

$I(t)$ is the irradiation amount, and $A_{c}$ is the surface area of the PV panel. The photovoltaic efficiency is tested and read immediately by the I-V measuring instrument. Hot water efficiency of the solar PV/thermal hybrid system, $\eta_{w}$, can be defined as:

$$
\eta_{w}=\frac{m_{w} C_{w}\left(T_{t}-T_{i}\right)}{\sum[I(t) \cdot \Delta t] \cdot A_{c}} \cdot 100 \%
$$

$m_{w}$ and $C_{w}$ are the weight and the specific heat of the water in the tank. $\Delta t$ is the interval of each experiment. $T_{i}$ and $T_{t}$ are the average water temperature of the tank before and after each experiment. The total photo-electric conversion efficiency, $\eta_{e, \text { total }}$, can be defined as:

$$
\eta_{e, t o t a l}=\eta_{e}+\eta_{c} \cdot \eta_{w}
$$

$\eta_{c}$ is the electric/heat energy conversion that is changed into the PV panel electric/heat conversion efficiency. According report to Ji et al. [11] and Huang [12], heat energy has lower conversion energy level than electric energy, and its $\eta_{c}$ is about 0.38. Namely, the hot water efficiency is about $38 \%$ of the photovoltaic efficiency. That is,

$$
\eta_{e, t o t a l}=\eta_{e}+0.38 \cdot \eta_{w}
$$

The structure of storage-type solar PV/thermal hybrid system is shown in figure 4. Thermal pad is set for conducting the waste heat from the PV panel to storage water tank. Experimental setup shows as figure 5. I-V curve is obtained by solar I-V measuring instrument of accuracy $\pm 1 \%$ reading value. Light source of halogen lamp is controlled by the angle inclination adjustment. Thermocouple of accuracy $\pm 0.1^{\circ} \mathrm{C}$ and infrared thermal imager of accuracy $\pm 2 \%$ are used to measure the water temperature of water tank and the surface temperature of PV panel respectively. Water tank is set below the PV panel to receive the waste heat directly, as shown in figures.

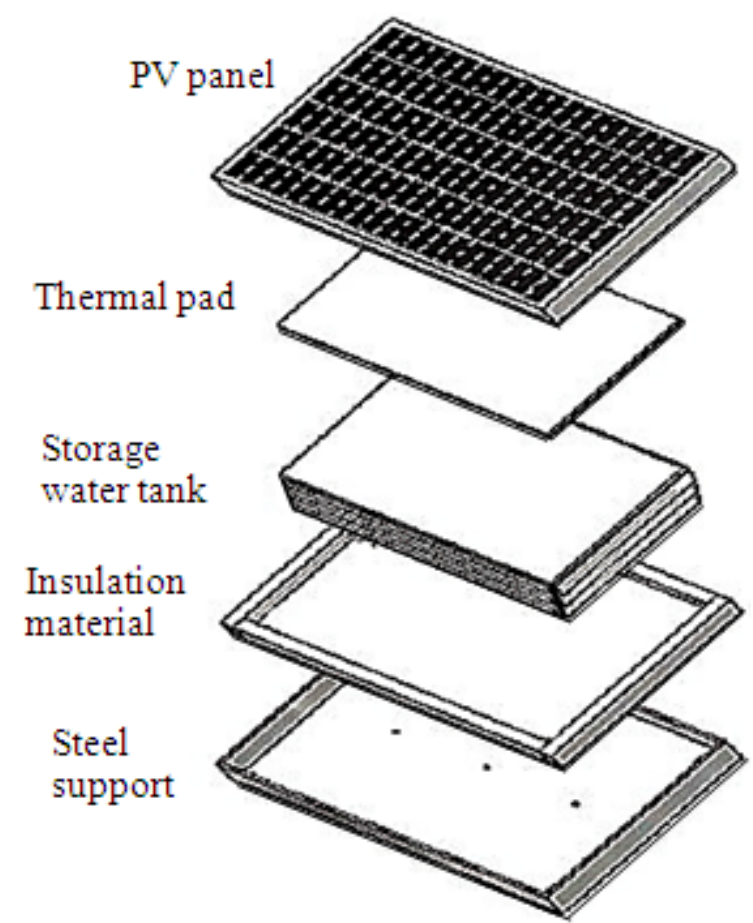

Figure 4. The structure of of storage-type solar PV/thermal hybrid system

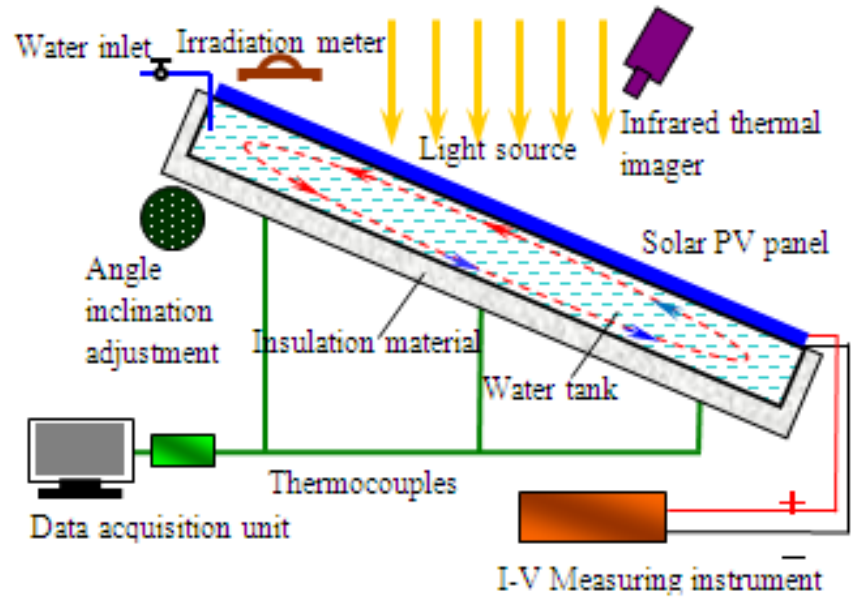

Figure 5. The experimental equipment setup of storage-type solar PV/thermal hybrid system 


\section{Results}

Characteristic analysis of storage-type solar PV/thermal hybrid system

The inclination angel of the solar PV panel is set to be $30^{\circ}$. The irradiation amount of $600,700,800$ and $900 \mathrm{~W} / \mathrm{m}^{2}$ used halogen light to simulate sunshine can be adjusted by tuner and measured by irradiation meter. Irradiation lighting for 60 minutes each experiment $\mathrm{I}-\mathrm{V}$ curves, as shown in figure 6 , were obtained by I-V measuring instrument at the irradiation adjusted $600 \sim 900 \mathrm{~W} / \mathrm{m}^{2}$. Closed-circuit current stably grows with the increase of irradiation amount; however, the open-circuit voltage is hold at a certain extent in spite of the different irradiation. The data of I-V curves show electric current drops to zero dramatically as output voltage is close to the open-circuit voltage at each irradiation amount. Short-circuit current is varied at different irradiation amount from $0.068 \mathrm{~A}$ to $0.179 \mathrm{~A}$. Electric current drops greatly at output voltage about $15 \mathrm{~V}$. As output voltage rises to the open-circuit voltage about $19 \mathrm{~V}$, electric current drops to $0 \mathrm{~A}$.

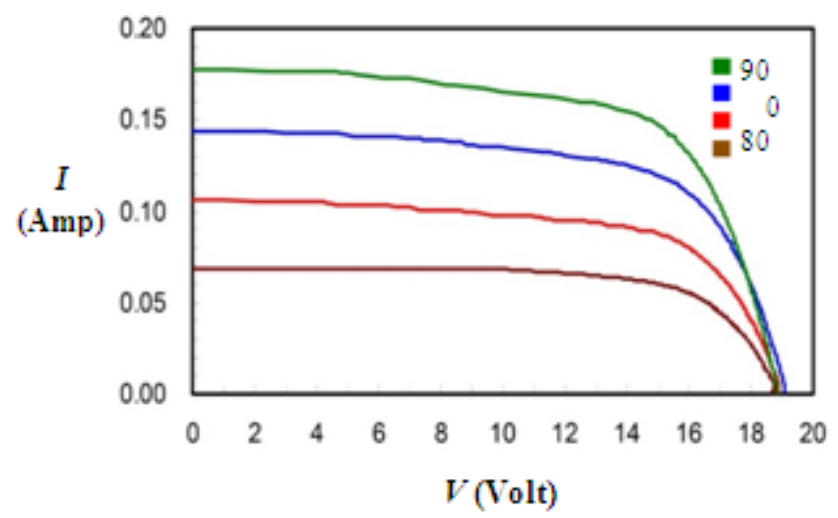

Figure 6. The correlation chart between current and voltage of PV panel of solar PV/thermal hybrid system as irradiation of $600 \sim 900 \mathrm{~W} / \mathrm{m}^{2}$

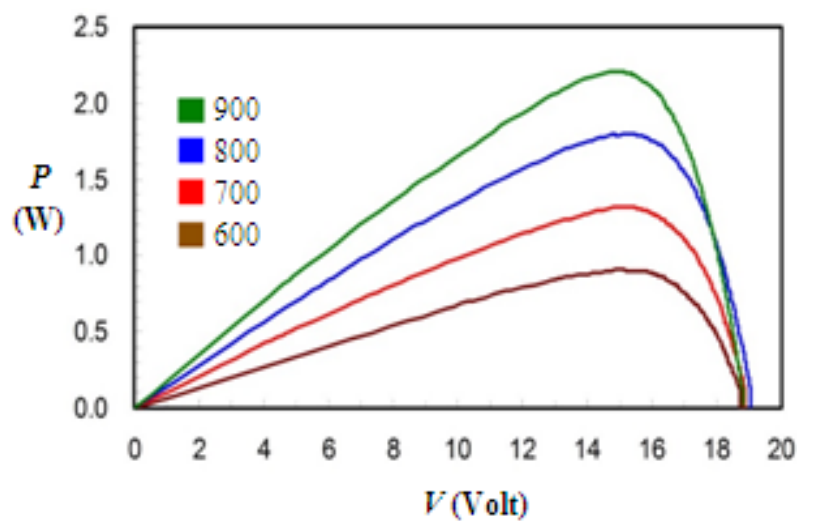

Figure 7. The correlation chart between output power and voltage of PV panel of solar PV/thermal hybrid system as irradiation of $600 \sim 900 \mathrm{~W} / \mathrm{m}^{2}$

The correlation between output power and voltage, as shown in figure 7 , were obtained also by I-V measuring instrument. Photovoltaic power stably grows with the increase of irradiation amount. The data of $\mathrm{P}-\mathrm{V}$ curves show photovoltaic power increases to the maximum value and drops to zero dramatically as output voltage is close to the open-circuit voltage at each irradiation amount. The point of maximum power is located at the output voltage about $15 \mathrm{~V}$. Maximum power is varied at different irradiation amount from $0.7 \mathrm{~W}$ to $2.2 \mathrm{~W}$.

Surface temperature distribution of PV panel in the storage-type solar PV/thermal hybrid system was imaged by infrared thermal imager. Imaging pictures of surface temperature of PV panel was captured in the last experiment period with different irradiation of $600 \sim 900$ $\mathrm{W} / \mathrm{m}^{2}$, as shown in figure 8 . The highest surface temperature located on the upper surface of the PV panel is 45.2 58.4 ${ }^{\circ} \mathrm{C}$. As we know, surface temperature of the PV panel is almost about $60 \sim 85^{\circ} \mathrm{C}$ generally when sun shines outside without cooling PV panel. The temperature of PV panel cooled in the storage-type solar PV/thermal hybrid system decreases very obviously. The result makes sure that photovoltaic efficiency of PV panel can maintain in the storage-type solar PV/thermal hybrid system. 


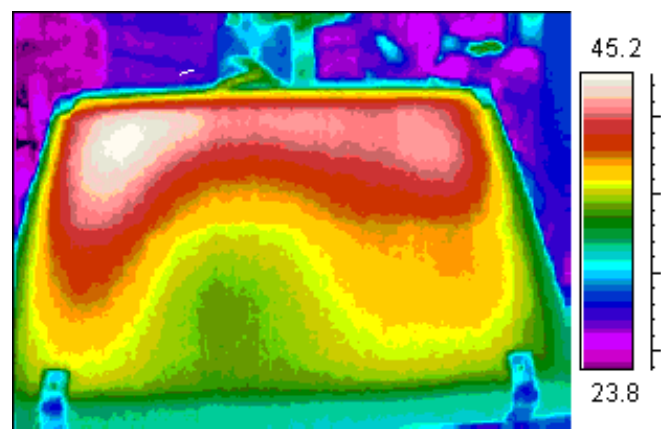

(a) $600 \mathrm{~W} / \mathrm{m}^{2}$

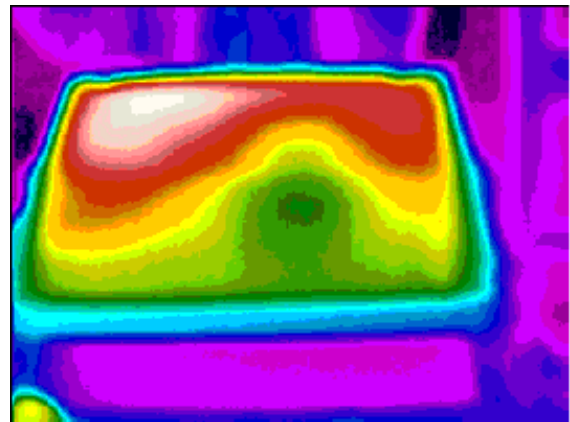

(c) $800 \mathrm{~W} / \mathrm{m}^{2}$

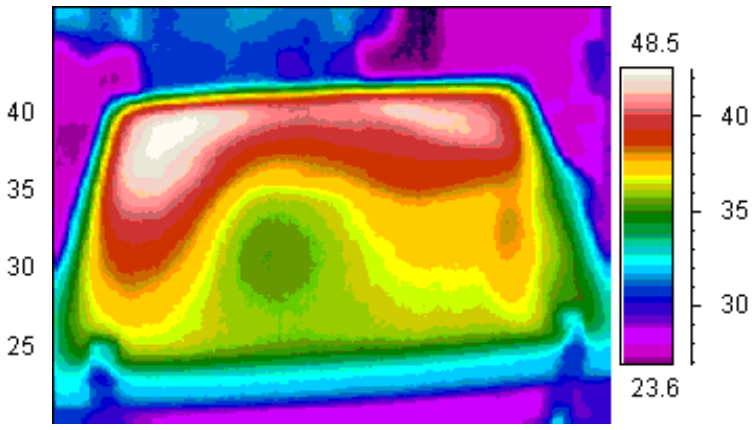

(b) $700 \mathrm{~W} / \mathrm{m}^{2}$

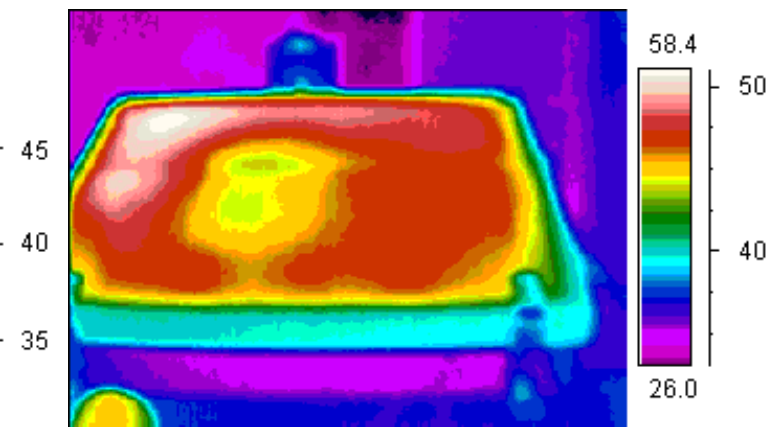

(d) $900 \mathrm{~W} / \mathrm{m}^{2}$

Figure 8. Imaging pictures of surface temperature of PV panel with different irradiation of $600 \sim 900 \mathrm{~W} / \mathrm{m}^{2}$.

Efficiency analysis of storage-type solar PV/thermal hybrid system

Experiment data of water temperature of storage-type $\mathrm{PV} /$ thermal hybrid system is listed in table 1, the interval of each experiment at irradiation lighting is for 60 minutes. The water temperature $T_{1}, T_{2}$ and $T_{3}$ are measured by thermocouples respectively on top, middle and bottom of the storage tank. Tavg is the average value of $T_{1}, T_{2}$ and $T_{3}$ water temperature. Average water temperatures Tavg increase with the increase of irradiation amount steadily. The data show the water temperature difference $\left(T_{t}-T_{i}\right)$ increases with the increase of time when halogen light shining on the PV panel. Table $1(\mathrm{a}) \sim(\mathrm{d})$ also shows the water temperature difference $\left(T_{t}-T_{i}\right)$ increases with the increase of different irradiation amount.

Photovoltaic efficiency of the PV panel, $\eta_{e}$, is read by measured the I-V curve with solar I-V measuring instrument at different irradiation amount. Hot water efficiency of the solar PV/thermal hybrid system, $\eta_{w}$, is calculated from equation (2-2) by the substitution of water temperature in the tank in table 1. For example, the weight $m_{w}$ and the specific heat of the water $C_{w}$ are $1.389 \mathrm{~kg}$ and $4200 \mathrm{~J} / \mathrm{kg}$ respectively. The value $\left(T_{t}-T_{i}\right)$ from table 1 is $15^{\circ} \mathrm{C}$ at the irradiation of $600 \mathrm{~W} / \mathrm{m}^{2}$. The interval of each experiment is 1 hour, and the $\Delta t$ value is brought $3600 \mathrm{~s}$ into equation (2-2). The surface area of the PV panel $A_{c}$ is 1060 $\mathrm{cm}^{2}$, and the value is brought $0.106 \mathrm{~m}^{2}$ into equation (2-2). So, the hot water efficiency $\eta_{w}$ is can be calculated as 0.3821 . Total photo-electric conversion efficiency, $\eta_{e}$, total, can be is calculated from equation (2-3) or (2-4).
The Various efficiency of storage-type PV/thermal hybrid system is listed in table 2. Though, heat energy increases with the increase of irradiation amount, hot water efficiency $\eta_{w}$ is maintained about $38 \sim 40 \%$. Because of experimental simulated light with halogen lamp in the Lab, pure photovoltaic efficiency $\eta \mathrm{e}$ is about $5 \sim 6 \%$. The electric/heat energy conversion efficiency $\eta_{c}$ is 0.38 , recycling hot water gets more electric/heat conversion efficiency $\eta_{c} \cdot \eta_{w}$ about $14 \sim 15 \%$. It reveals that the hot water conversion efficiency of storage-type PV/thermal hybrid system is almost triple than pure solar photovoltaic efficiency. Total efficiency $\eta$,total calculated is about 19 21\%. The results show that total efficiency $\eta_{e, t o t a l}$ is almost 4 times as compared to the pure photovoltaic efficiency $\eta_{e}$.

Table 1. Water temperature in the tank of storage-type solar PV/thermal hybrid system
(a) Irradiation $600 \mathrm{~W} / \mathrm{m}^{2}$

\begin{tabular}{|c|c|c|c|c|c|c|}
\hline $\begin{array}{l}\text { Temperature } \\
\left({ }^{\circ} \mathrm{C}\right)\end{array}$ & $\begin{array}{c}0 \\
\left(T_{i}\right)\end{array}$ & 15 & 30 & 45 & $\begin{array}{c}60 \\
\left(T_{t}\right)\end{array}$ & $\left(T_{t}-T_{i}\right)$ \\
\hline$T_{1}$ & 27.5 & 28.3 & 29.1 & 34.7 & 38.7 & 11.2 \\
\hline$T_{2}$ & 27.1 & 27.5 & 31.3 & 38.5 & 42.9 & 15.8 \\
\hline$T_{3}$ & 27.3 & 31.7 & 35.1 & 41.9 & 45.4 & 18.1 \\
\hline$T_{\text {avg }}$ & 27.3 & 29.1 & 31.8 & 38.3 & 42.3 & 15.0 \\
\hline
\end{tabular}


(b) Irradiation $700 \mathrm{~W} / \mathrm{m}^{2}$

\begin{tabular}{|c|c|c|c|c|c|c|}
\hline $\begin{array}{c}\text { Temperature } \\
\left({ }^{\circ} \mathrm{C}\right)\end{array}$ & $\begin{array}{c}0 \\
\left(T_{i}\right)\end{array}$ & 15 & 30 & 45 & $\begin{array}{c}60 \\
\left(T_{t}\right)\end{array}$ & $\left(T_{t}-T_{i}\right)$ \\
\hline$T_{1}$ & 27.0 & 27.8 & 31.4 & 35.0 & 40.6 & 13.6 \\
\hline$T_{2}$ & 26.9 & 28.7 & 33.0 & 39.5 & 44.8 & 17.9 \\
\hline$T_{3}$ & 26.8 & 31.2 & 40.6 & 45.0 & 48.7 & 21.9 \\
\hline$T_{\text {avg }}$ & 26.9 & 29.2 & 35.0 & 39.8 & 44.7 & 17.8 \\
\hline
\end{tabular}

(c) Irradiation $800 \mathrm{~W} / \mathrm{m}^{2}$

\begin{tabular}{|c|c|c|c|c|c|c|}
\hline $\begin{array}{l}\text { Temperature } \\
\left({ }^{\circ} \mathrm{C}\right)\end{array}$ & $0\left(T_{i}\right)$ & 15 & 30 & 45 & $\begin{array}{c}60 \\
\left(T_{t}\right)\end{array}$ & $\left(T_{t}-T_{i}\right)$ \\
\hline$T_{1}$ & 25.8 & 29.5 & 32.8 & 37.8 & 40.9 & 15.2 \\
\hline$T_{2}$ & 25.6 & 31.7 & 34.1 & 41.1 & 45.0 & 19.4 \\
\hline$T_{3}$ & 25.5 & 32.3 & 38.4 & 47.7 & 52.9 & 27.4 \\
\hline$T_{\text {avg }}$ & 25.6 & 31.1 & 35.1 & 42.2 & 46.2 & 20.6 \\
\hline
\end{tabular}

(d) Irradiation $900 \mathrm{~W} / \mathrm{m}^{2}$

\begin{tabular}{|c|c|c|c|c|c|c|}
\hline $\begin{array}{l}\text { Temperature } \\
\left({ }^{\circ} \mathrm{C}\right)\end{array}$ & $\begin{array}{c}0 \\
\left(T_{i}\right)\end{array}$ & 15 & 30 & 45 & $\begin{array}{c}60 \\
\left(T_{t}\right)\end{array}$ & $\left(T_{t}-T_{i}\right)$ \\
\hline$T_{1}$ & 26.5 & 28.2 & 33.0 & 38.9 & 43 & 16.5 \\
\hline$T_{2}$ & 26.8 & 32.4 & 38.8 & 42.1 & 47.6 & 20.8 \\
\hline$T_{3}$ & 26.8 & 34.6 & 45.5 & 49.6 & 56.0 & 29.2 \\
\hline$T_{\text {avg }}$ & 26.7 & 31.7 & 39.1 & 43.5 & 48.8 & 22.1 \\
\hline
\end{tabular}

Table 2. Efficiency data of storage-type PV/thermal hybrid system at different irradiation amount

\begin{tabular}{|c|c|c|c|c|}
\hline $\begin{array}{l}\text { Irradiation } \\
\left(\mathrm{W} / \mathrm{m}^{2}\right)\end{array}$ & $\eta_{e}$ & $\eta_{w}$ & $\eta_{c} \cdot \eta_{w}$ & $\eta_{e, \text { total }}$ \\
\hline 600 & 5.18 & 38.21 & 14.51 & 19.70 \\
\hline 700 & 5.14 & 38.82 & 14.75 & 19.89 \\
\hline 800 & 5.23 & 39.35 & 14.95 & 20.18 \\
\hline 900 & 5.35 & 39.00 & 14.82 & 20.17 \\
\hline
\end{tabular}

\section{Conclusions}

Storage-type solar PV/thermal hybrid system is set up to cool the surface of PV chip and reuse the waste heat. Surface temperature of PV panel has been cooled decreases obviously as shown with IR thermal imager in the storage-type solar PV/thermal hybrid system. The result makes sure that the photovoltaic efficiency of PV panel can maintain in the storage-type solar PV/thermal hybrid system.

Total efficiency transformed by the photovoltaic efficiency and hot water efficiency. The results show that total efficiency in experiment is more excellent as compared to the pure photovoltaic efficiency. The hot water efficiency of PV/thermal hybrid system from recycling waste heat gets $38 \sim 40 \%$, and the electric/heat conversion efficiency gets about $14 \sim 15 \%$. In real sunshine surrounding, photovoltaic efficiency of PV chip is about $10 \sim 15 \%$ at the irradiation of
$600 \sim 900 \mathrm{~W} / \mathrm{m}^{2}$. It shows, though in real sunshine surrounding, the total efficiency of storage-type PV/thermal hybrid system is more twice than pure solar photovoltaic efficiency.

\section{Acknowledgements}

This research was supported by the Ministry of Science and technology, Republic of China, under Grant No. MOST 103-2221-E-236-015

\section{REFERENCES}

[1] Sangani CS, Solanki CS: Experimental evaluation of V-trough (2 Suns) PV concentrator systems using commercial PV modules," Sol. Energy Mater. Sol. Cells. 2007; 91: 453-459.

[2] Solanki CS, Sangani CS, Gunashekar D, Antony G: Enhanced heat dissipation of V-trough PV modules for better performance," Solar Energy Materials \& Solar Cells. 2008; 49:1634-1638.

[3] Akbarzadeh A, Wadowski T: Heat pipe-based cooling systems for photovoltaic cell under concentrated solar radiation, Applied Thermal Engineering. 1996; 16(1):81-87.

[4] Abrahamyan YA, Serago VI, Aroutiounian VM, Anisimova ID et al.: The efficiency of solar cells immersed in liquid dielectrics," Sol Energy Mater Sol Cells. 2002; 73:367-75.

[5] Muaddi JA, Jamal MA: Spectral response and efficiency of a silicon solar cell below water surface, Sol Energy. 1992; 49:29-33.

[6] Krauter, S., Hanitsch, R., Moreira, L., New optical and thermal enhanced PV modules performing $12 \%$ better under true module rating conditions, Proceedings of the 25th IEEE - PV - Specialists Conference, Washington DC, USA. 1996; May 13-19:1323-1326.

[7] Krauter S: Increased electrical yield via water flow over the front of photovoltaic panels, Solar Energy Materials \& Solar Cells. 2004; 82:131-137.

[8] Hollick JC: Solar cogeneration panels, Renew Energy. 1998; 15:195-200.

[9] Tonui JK, Tripanagnostopoulos Y: Ventilation benefit accrued from PV module installed in building, Proceedings of the international conference on passive and low energy cooling for built environmental, Santorini, Greece. 2005; May1921:861-866, 2005.

[10] Kumar S, Tiwari A: Design, fabrication and performance of a hybrid photovoltaic/thermal (PV/T) active solar still Original Research Article, Energy Conversion and Management. 2010; 51(6):1219-1229.

[11] Ji J, Ping J, Lu T et al.: A sensitivity study of a hybrid photovoltaic/thermal water heating system with natural circulation, Applied Energy. 2007; 84:222-237.

[12] Huang BJ: Performance evaluation of solar photovoltaic/thermal systems, Solar Energy. 2001; 70: 443-448. 